Elsevier required licence: (C) <2018>. This manuscript version is made available under the CC-BY-NC-ND 4.0 license http://creativecommons.org/licenses/by-nc-nd/4.0/ 


\title{
Re-conceptualizing Barriers to Travel by People with Disabilities
}

Bob McKercher, Simon Darcy

December, 2017

Please reference

McKercher, B., \& Darcy, S. (2018). Re-Contextualizing Barriers to Travel by People with Disabilities. Tourism Management Perspectives,26 ( pp59-66)

https://doi.org/10.1016/j.tmp.2018.01.003

\begin{abstract}
s
This paper proposes a four-tiered hierarchy to understand better the nature and effects of barriers, constraints and obstacles to travel faced by people with disabilities. Previous studies tended to aggregate barriers into a single group and further, some research associated barriers faced by all tourists as being unique to people with disabilities. The failure to recognise the complex, yet subtle interplay between tourism and different types of barriers results in the tendency to see people with disabilities as a homogeneous group where a one size fits all solution applies. In reality, they are a heterogeneous cohort who face the same types of barriers as everyone, some barriers that are common to all people with disabilities, those that are unique to each disability dimension and specific impairment effects that are individualistic.
\end{abstract}

Keywords: disability; constraints; barriers; disability studies; tourist experience

\section{Introduction}

The World Health Organization (WHO) estimates that more than one billion people worldwide can be classified as having a disability, with up to 190 million experiencing significant difficulties in functioning (WHO 2015). This figure is expected to increase as a causal link exists 
between aging and the onset of disabilities (Patterson \& Pegg 2011). The WHO recognizes further that a range of obstacles, barriers and/or constraints hinder their full and effective participation in society. Within a tourism context, a large number of studies have also identified barriers as one of the many reasons why participation rates in and qualities of experience of tourism are lower than that of the general population (see Buhalis \& Darcy 2011 and UNWTO 2016 for a summary of these studies).

Much of this research tends to regard people with disabilities as a largely homogeneous group "as if every person with a disability possessed the same constraints and has to overcome the same barriers (Figueiredo, Eusebio \& Kastenholz 2012: 534)." Yet, Darcy \& Buhalis (2011) remind us first that disabilities can be classified into a wide array of categories and second, that within each category, the degree of ability exists along a continuum based on the individual's level of support needs. Much of this research also identifies the types of barriers noted in the general tourism and leisure constraints literature as being unique to people with disabilities (PWD), when in fact they are issues all tourists must resolve. As a result, there is a tendency in the literature to adopt a one-size fits all approach to constraints research, which as Eichhorn \& Buhalis (2005) observe has hindered the systematic understanding, analysis and resolution of issues faced by people with different types of disabilities.

This paper proposes that we should adopt a more holistic perspective by disaggregating constraints and, instead, grouping them hierarchically into a four-tiered framework (Figure 1). Each tier represents an increasing level of specificity beginning with constraints faced by all and ending with the consideration of specific impairment effects (Thomas, 1999, 2004) that are highly individualistic. The model is conceptual in nature based on a critical review of the literature, the authors' own research, the lived experience of one author and the other author's experience of travelling with PWD. The paper begins by examining the many contextual challenges involved in the development of such a framework. Each of the tiers is then discussed and the paper concludes with an overview of the model's implications for future research.

Insert Figure 1 about here 


\section{Contextual challenges}

A number of contextual challenges arise when discussing barriers to travel by people with disabilities. To begin, the paper adopts a social model of disability whereby the types of constraints identified are imposed on those with impairments by society, more so than 'disability' being a function of a medical condition (Barnes, Mercer, \& Shakespeare, 2010; Oliver, 1990). It acknowledges that social approaches of environments (physical, economic, social, cultural etc.) are disabling by their nature and that people with disabilities are exposed to hostile social attitudes that overtly and covertly constrain participation. Together the disabling environments and hostile attitudes are imposed on top of an individual's impairment creating 'disabled people' (Oliver, 1990; Barnes, Mercer \& Shakespeare, 2010), rather than people who happen to have a disability. The materialist or critical theory underpinnings of the social model focus on the way that organisations, structures, processes and practices exclude, omit, overlook or deliberately discriminate against people with disability. (See Shakespeare 2017 for a deeper discussion of this issue).

The social model further highlights a number of linguistic, subjective and emotive challenges that arise when trying to develop a framework to assess barriers. Very little is absolute in this issue, and as with much foundation work in other tourism topic areas, early works have laid the foundation for future studies up to the current time, even if they have been proven to be conceptually deficient (McKercher \& Prideaux 2014). One example is Smith's (1987) original work which built on leisure studies research with little discussion of the conceptualisations of disability. Here, the focus along with other early studies by Muloin (1992) and Murray \& Sproats (1990) was disproportionately on people with mobility disabilities with high or very high support needs.

Likewise, there seems to be an enduring belief in the homogeneity of disabilities and therefore the provision of a one-size-fits-all solution (Figueiredo et al 2012). This situation has been 
noticed in works by Bergier \& Kubinska (2010), Richards, Pritchard \& Morgan (2010), Lee et al (2012), and Ray \& Ryder (2003) which involved studies of people with different types of disabilities, but resulted in the proposition of a homogenized conclusion. Yet, Darcy, Ambrose, Schweinsberg \& Buhalis (2011:304) note that "within the seemingly narrow World Health Organization's categories, literally thousands of conditions can be diagnosed for an individual's lack of ability." For example, the Australian Human Rights Commission that administers the Disability Discrimination Act, 1992 states the definition of disability in the Act includes those with physical (mobility); intellectual; psychiatric (mental health); sensory (vision and hearing); neurological; and learning disabilities, plus; physical disfigurement; and those with the presence in the body of disease-causing organisms. These categories are based on data collection from the WHO biopsychosocial approach, which is predominantly impairment based and then aggregated into 'body functions/structures' (WHO 2001; 2002).

'Disability' also exists along a continuum from those with all types of disability who need no support needs to those with profound restrictions who may need 24 hour support (Darcy \& Buhalis, 2011; Dwyer \& Darcy 2011, CSD 2015). The Australian Bureau of Statistics identifies five categories of 'severity of disability' including none, mild, moderate, severe, or profound (Australian Bureau of Statistics, 2015). Dwyer \& Darcy (2011), for example, report Australian Bureau of Statistics figures identified that $20 \%$ of the Australian population has a disability but $50 \%$ of that figure are people with disability who have no or only mild support needs, while about $15 \%$ have profound needs or $3 \%$ of the overall population. The Hong Kong Census and Statistics Department (CSD 2015) states about one-quarter of people with restrictions in body movements always require a wheelchair, while half do not require any type of specialist tool or need one occasionally. Likewise, less than $5 \%$ of people with vision difficulties are unable to see at all and fewer than $3 \%$ of people with hearing difficulties are completely deaf. And so, while the numbers of PWD may seem high, in reality, only the relatively smaller share of those with moderate, high or very high support needs may require specialist tourism products and services (Darcy \& Buhalis, 2011; Darcy, Ambrose, Schweinsberg \& Buhalis, 2011). 
Finally, barriers and constraints are not absolute. Thirty years ago, McGuire, Dottavio \& O'Leary (1986) noted the impact of any constraint is dependent on how people react to it. In some cases, the same constraint may prohibit participation; in other cases it may limit the range of activities; and in other cases still, it may be a non-issue. The key difference between prohibiting and a limiting factor is that one may stop travel in whole or preclude people from visiting certain places, while the other may affect the frequency, types of activities engaged in, or satisfaction (Small et al 2012, UNWTO 2016). Each may or may not be successfully negotiated either by choosing strategies or by making personal compromises to enable participation (Daniels, Drogin Rodgers \& Wiggins 2005; Mactavish, MacKay, Iwasaki \& Betteridge 2007; Yau, McKercher \& Packer, 2004). Moreover, a person who might have low ability in one area (e.g. mobility) might have exceptionally high ability in another (e.g. intelligence or seeing) (Buhalis et al 2005).

And yet, an apparent belief held by many in industry is that resolving mobility access issues represents a universal template to resolve all other issues. The O'Neill \& Knight (2000) study of hotels in Western Australia, for example, found 96\% of properties surveyed had a clear and accessible route to the reception desk, but only $29 \%$ had any facilities for people with sight or hearing impairments. In an extreme example, Richards et al (2010) reported a visually impaired couple were forced to sit in a wheelchair to be assisted through an airport when they were capable of walking. Interestingly, and ironically, ignorance also fuels the impression that people with disabilities should look and act in a certain way to 'prove' they are disabled enough to qualify for assistance. Some people have reported that they feel like frauds because they do not use social signifiers of their disability or behave in a stereotypical manner (Darcy, 2012; McKercher et al 2003, Poria et al 2009, Richards et al 2010).

\section{A Four tiered-framework}

The net result is that any comprehensive examination of barriers or constraints faced by PWD involves a level of complexity and subtlety not typically addressed in the literature. One reason is the heavy focus of research on people with physical or mobility disabilities and, by comparison 
the relative neglect given to other types of disabilities (O’Neill \& Knight 2000), including vision and hearing (Zajadacz, 2015; Small, Darcy \& Packer 2012), families with children (Kim \& Lehto 2012), people with intellectual disabilities (Mactavish, MacKay, Iwasaki \& Betteridge 2007) and others. While many excellent frameworks have been developed identifying the types of disabilities and range of support needs required as identified by Buhalis \& Darcy (2011), no broadly based framework has been developed that considers the relationship among different types of disabilities and barriers.

The four tiered framework discussed in this paper seeks to add further structure to our understanding of this issue. It can be divided roughly into three parts, with the first tier reflecting issues faced by all tourists, the second tier identifying constraints that are common to all PWD regardless of the disability and the last two tiers focusing exclusively on individual types of disabilities and associated impairment effects.

\section{Tier 1: Barriers Faced by All Tourists}

A variety of studies show few differences exist in the desire for and motives to travel between PWD and the general population (Buhalis et al 2005, Ray \& Ryder 2003, Small et al 2012, Yau et al 2004). By extension, then, the same types of generic barriers that affect the general population should also apply to PWD, although they may be felt more acutely by them. These types of barriers have emerged from leisure constraints theory, which, in its simplest form assumes obstacles prevent people from travelling, and if the obstacles could be removed or successfully negotiated, non-travelers would become travelers (Nyaupane \& Andereck 2008). Constraints are typically classified into one of three hierarchical categories of: intrapersonal, interpersonal, and structural (Crawford \& Godbey 1987, Crawford, Jackson \& Godbey 1991). Intrapersonal barriers include a range of psychological factors including religion, reference group attitudes and perceived self skill, health and lack of interest. Interpersonal constraints focus primarily on the presence of travel partners and interpersonal communication, while structural constraints consider such things as time, cost, lack of opportunity and family commitments. 
Jackson et al. (1993) evaluated this model from a tourism context, while it has also been used by a number of other researchers (Hudson \& Gilbert 2000, Nyaupane \& Andereck 2008).

McKercher \& Chen (2015) suggest that, in a tourism context, lack of interest should be disaggregated from the basket of intrapersonal constraints and identified as a discrete category in its own right, resulting in the creation of four levels of generic constraints. Their research showed no amount of barrier removal will engender travel if the person simply has no interest in this activity, or if interest is not a high enough priority to engender action. Corroborating evidence in support of the proposition to separate interest comes from Litvin, Smith \& Pitts (2013) and Dolnicar, Lazarevski \& Yanamandram (2013), while an earlier study by McKercher (2009) concluded people tended to identify socially acceptable intrapersonal constraints to mask a lack of interest in travel.

The triad of intrapersonal, interpersonal and structural constraints has been identified explicitly in disability studies (Daniels, Rodgers \& Wiggins 2005; Lee et al 2012; Small et al 2012) and is implicit in many others. Darcy, Ambrose, Schweinsberg \& Buhalis (2011) also adopted this model to conceptualise access enablers, which focus on negotiating perceived barriers or constraints. Clearly, some of these types of constraints may be felt more acutely by PWD that others. For example, many people with disability have lower levels of employment and live well below the poverty line (World Health Organization \& World Bank, 2011) and, hence, financial and economic constraints are likely to be a more significant Tier 1 barrier. But financial ability is applicable to anyone who lives below the poverty line. Likewise, reference group attitudes and perception of self skill emerge as particularly relevant intrapersonal considerations, especially regarding the perceived right to travel (Kastenholz et al. 2015; McKercher, Packer, Yau \& Lam 2003; Murray \& Sproats 1990), but have also been identified as reasons why some seniors and recently married women in Asia do not feel they have the right to travel any more (Lee \& Tideswell 2005; Mak, Carlisle, \& Dai 2005).

Likewise, Smith (1987) identified lack of travel partners as a critical interpersonal issue, but lack of travel partners affects everyone, potentially. More recent studies question its importance in a 
tourism (Daniels et al 2005) and sport context (Darcy, Lock \& Taylor, 2017). Instead, the issue may be embedded better as a cost consideration as part of the structural barrier category with respect to paid attendant caregivers (Darcy, 2002; Small, 2015). In general, the costs of travel are higher for people with disabilities (Freeman \& Selmi 2010; Kastenholz et al 2015; Yau et al 2004), with Luther (2013) estimating somebody with a high level spinal injury may incur between $30 \%$ and $200 \%$ higher, depending on medical, physical therapy and associated equipment needs (e.g. shower chairs, hoists etc.). The need to cover the costs of attendant caregivers is just one reason (Lee, Agarwal \& Kim 2012), while international caliber hotels usually have better accessible facilities than lower grade properties, but come at a higher price (Darcy, 2010; Yau et al 2004) is another reason.

\section{Tier 2: Issues Faced By All People with Disabilities}

While everyone has to deal with interest, intrapersonal, interpersonal and structural constraints to a greater or lesser degree, people with disabilities have to deal with a range of issues not faced by the general public. The second tier of constraints relates to issues that are common to them as a collective, regardless of their disability. The literature identifies five broad categories, including: ignorance; attitude; trustworthiness of information; issues related to the tourism industry itself, and; the person. Each is briefly discussed below and while discussed separately should be considered interdependent and overlapping. Again, some issues, such as information trustworthiness, may seem to be applicable to the general population, depending on the context, but their impact on this population is far greater due to information specificity and detail.

\section{Ignorance - overlooked, omitted or othered}

Ignorance is arguably the most significant issue for it is the proximate cause of most other problems associated with attitude, information and industry reaction. Ignorance can be traced to observations of disability, stigma and the other where disability is not seen as part of the diversity of 'normal' society (Goffman, 2010; Thomson, 1997). Many people have little or no exposure to disability, do not know individuals with disability or have any understanding of 
disability issues. Ignorance crosses the boundary to all aspects of the professional world, including tourism, where disability becomes overlooked, omitted or othered (Darcy \& Pegg 2011). Richards et al (2010) add that many people in industry have never met people with disabilities in either their personal or professional lives. It is for this reason that the UN World Tourism Organization (UNWTO 2016), along with advocacy groups and tourists alike call for greater training, awareness building and exposure. In particular contact theory suggests that those who have contact with or experience interaction with people with disability are associated with a more positive attitude formation towards the group (Daruwalla \& Darcy, 2005; Pettigrew \& Tropp, 2006). Daruwalla \& Darcy (2005) tested the importance of awareness training interventions on tourism and hospitality students, and tourism professionals in a major organisation, with both groups showing changes in attitude towards people with disability after awareness training interventions involving information, video and personal contact. While attitude change occurred after awareness training with information and video resources, it was more prevalent and longer lasting after person contact.

Ignorance, in turn, fuels many misconceptions about the level of ability, for a commonly held belief is that any disability equates to total disability, the need for a high degree of assistance (O'Neill et al 2000, Ray \& Ryder, 2003, Richards et al 2010, Small et al 2012, Yau et al 2004) and sometime associated psychological or intellectual disability. The Nicolaisen et al (2012) study, for example, found that almost half of the industry people interviewed defined disability as equating to something similar to total and permanent inability to function in daily life. This belief, in turn, fuels a number of misconceptions about the level of support needed, often leads to inappropriate attention or behavior that can produce service failures, and unsolicited employee conduct (Kim \& Lehto, 2012). Most people with disabilities are quite adventuresome in their travel wishes (Ray \& Ryder 2003), and moreover live healthy lives. People with disability are not permanently sick (they get ill like everybody else) and participate in all types of social activities when the economic, social and structural environment provides enablers to support their participation (e.g. Ramps, Braille, hearing loops et cetera). 


\section{Attitude}

Ignorance expresses itself in a series of negative attitudes and overt or covert discrimination, so much so that some people with disability choose either to hide or not disclose their disabilities from service providers (McKercher et al 2003). Indeed, negative attitudes emerge as the single greatest issue in many studies (McKercher et al 2003, Lyu Oh \& Lee 2013; Small et al 2012) and conversely a 'can-do customer service attitude' regarded as the most important attribute of service delivery (Darcy, 2010). The source of these attitudes is manifest, although it appears a core reason is the widespread adoption of a medical rather than social approach to disability whereby attitudes are driven more by the belief that the issue lies more within the individual rather than with how society treats the disability. The result is a belief that people with disabilities need to conform or adapt themselves, rather than suggesting society should understand the diversity of ability or be designed to be inclusive of their embodiment (Nicolaisen, Blichfeldt \& Sonnenschien 2012). However, there is also evidence that significant differences in attitudes exist in different cultures that affect the level of prejudice people face and their relative invisibility in the community (Bolt, 2014).

Overt or subtle discrimination and social exclusion are the main outcomes of negative attitudes (Yau et al 2004), making many people feel like they are being treated differently than others (Shaw \& Coles 2004; Darcy \& Taylor, 2009), and ultimately adding an extra dimension of stress to the experience while reducing overall satisfaction (Small et al 2012; Darcy, 2012). Ignorance also produces one of two common reactions. On the one hand, many people claim they are simply disregarded and ignored (Richards et al 2012). On the other hand, it induces fear, or misapprehension among others, for as Freeman \& Selmi (2010: 479) write "the public's attitudes are the largest impediment for the mentally challenged. People treat our clients like they can catch it." This issue is an ongoing one that defies simple resolution, for as Daruwalla \& Darcy (2005) note, corporate attitudes may change quickly, but personal ones will change much more slowly and are largely dependent on increased positive contact with people with disabilities. 


\section{Trustworthiness of Information}

In addition, trustworthiness of information creates some pragmatic impediments to participation, or at least to full participation (Daniels et al 2005). Lack of information, in general, and the trustworthiness of such information were identified second only to prevailing attitudes as barriers to travel (Daniels et al 2005, Lee et al 2012). Adequacy and accuracy of information affect all stages of the travel planning process, for what is portrayed as being accessible is not always accessible, especially in the hotel sector (Darcy 2010; Ray \& Ryder 2003). Properties may promote themselves as being accessible yet on arrival the client discovers that they are only partially accessible, or so-called accessible facilities are located in remote or out-of-the-way places (Darcy, 2010). In other instances, what is ostensibly accessible becomes inaccessible through attempts to improve the aesthetics by such actions as installing thick carpeting, low lighting, music, steps and other architectural improvements (Darcy 2013, Richards et al 2010). Many who require alternative information provision (e.g. accessible websites for people who are blind) find accessing such information particularly in online environments problematic (Buhalis \& Michopoulou, 2011; Dickson, Darcy, Johns \& Pentifallo, 2016; Mills, Han, \& Clay, 2008; Shi, 2006; Williams, Rattray, \& Grimes, 2006; Zajadacz, 2014)

\section{Industry ignorance}

The complicity of industry in creating unnecessary barriers, directly or indirectly has to be acknowledged. Kastenholz et al (2015) conclude that the structure of the sector reinforces the self sentiment of being different which further leads to social exclusion on trips. McKercher et al (2003) raise this issue specifically in relation to the travel trade, where the structural realities of running high volume, low margin businesses result in the needs to process people as quickly and efficiently as possible. Many travel agents, therefore, feel they cannot provide the type of services needed by people with disabilities. They also noted that the inflexible nature of many package tours, with the early starts, multiple short stops during the day and often late finishes precludes some people from participating fully in the trips, or forces them to make compromises to cope with the itinerary. Ignorance also fuels the belief among some people in industry that 
only specialist providers are capable of meeting needs (Daniels et al 2005, Kim \& Lehto 2012, Lee et al 2012; Zajadacz 2015). The extreme example is where operators in some countries refuse to serve people with disabilities and instead suggest that they should look to these types of providers (Darcy 1998; Yau et al 2003). Notwithstanding this observation, though, general awareness still seems to be rather low, especially of the specific, discrete needs to cater for people with different types and level of disability (Darcy; 2010; Darcy \& Pegg, 2011; O'Neill \& Knight, 2000).

\section{Tier 3: Issues Unique to Specific Disabilities}

A defining element of social approaches to disability is that people only become 'disabled' when faced with barriers that are imposed on top of their underlying 'impairment'. The UN Convention on the Rights of Persons with Disability (2006), for example, indicates disability becomes evident when a person encounters economic, social, cultural or environmental barriers while trying to participate in social activities. On this basis, people with different types of disability may face challenges that are unique to their type. Thus, what may be a critical issue for someone with one type of disability, may be irrelevant to some else with a different type. For example, those who have mobility issues and use wheelchairs have specific requirements for accommodation (e.g. roll in shower) while someone who is deaf does not need those types of support but has other support needs (e.g. visual alarms). Hence, the need for the identification of a of a third tier in the hierarchy that recognizes people may have to address different barriers depending on their disabling condition. The following section discusses briefly some unique needs using four groups as exemplars.

\section{Physical or Mobility}

Architectural and design issues are especially important for people with mobility disabilities, be they skeletal or neurological. Steps, uneven ground surfaces, the need for ramps, splash barriers and toilets, bed heights, showers, and a range of other obstacles (Darcy 2010, Figueiredo et al 2012) may present impediments to full participation. A range of issues associated with air travel, 
especially relating to effectively transferring passengers from wheelchairs to seats and vice a versa and the often painful and humiliating experience of going to the bathroom (Chang \& Chen 2011, Darcy, 2012; Poria, Reichel \& Brandt 2010), may also create impediments and/or obstacles. Further, the movement of wheelchair users on charter services or specialist attractions has also proved problematic where transport and carriage design has not incorporated international standards of access and mobility. Hence, people with physical or mobility disabilities have not been able to fully experience the breadth of environmental offerings in destinations.

\section{Vision}

The person with a vision disability has to overcome the broadly held perception that because he or she cannot see, then the person cannot appreciate travel fully (Small et al 2012). As such, the need to provide meaningful experiences through touch, smell, taste and hearing becomes critical (Figueiredo et al 2012). The standard type of architectural solutions provided for people with mobility barriers are not particularly relevant for the visually impaired. Instead, they need a range of audible augmentation devices, teletext decoders, and sensory or tactile markers and the like (Chang \& Chen 2011, O'Neill \& Knight 2000). Trust also emerges strongly among this group of tourists (McKercher et al 2003), especially when riding public transport or taxis, for the fear of being cheated, overcharged or dropped off in an unknown locality is heightened.

Many sighted people cannot even conceptualise the unsighted could travel. However with an understanding of the other senses there are many elements of tourism that people who are blind or have vision impairment can experience and want to experience through the ambience, sights and sounds, aromas and tactility offered by destination regions. While many stop at supports such as Braille signage, a more nuanced understanding of the market is required where only a small proportion of people with vision impairment can use Braille (Richards et al 2010; Small et al. 2012; Small 2015), for learning Braille involves learning a whole new language. Hence, the importance of websites that have been built to allow screen readers to read out the website via software to people with vision impairment or who are blind are essential for travel planning. 


\section{Hearing}

A similar same situation applies to many auditorially-impaired people. Again, architectural solutions are of little consequence to them. But, they too require a range of assistive technologies has been transforming alternative communication for these groups and providing new opportunities for embodied tourism experiences (e.g. real-time captioning). In addition, more personalised communication is needed when travelling for announcements about flight and train arrivals may not be heard. Text messaging has provided a service enhancement for this group that many travel companies adopt as standard practice together with Twitter, Facebook and other social media and that is text based. The assumption that people with hearing impairments can read lips is false (Freeman \& Selmi 2013), while learning to sign involves the acquisition of an entirely new language and there are differences in sign language between countries.

\section{Intellectually or Physically Disabled Children}

Parents of children with intellectual, mental health or high support physical disabilities face such a large array of issues that many wonder if travel is worth it, for the effort involved in organising the logistics of medical care, and ensuring that appropriate services are available may outweigh the benefits (Mactavish et al 2007). Parents also cite the challenges of organising suitable childcare as an inhibitor. Kim \& Lehto (2012) write about how travel can be disruptive for children used to a routine and how the need to cater to both the child with a disability and children without disabilities can create added stress. Perry \& Kozub (2011) add families need added flexibility in case the stimulation of travel creates behavioural problems among children on the autism spectrum, especially if they have to stand in line for a long time. They also add that hotel security and locks on hotel room windows are important for some families in case their children wander.

In particular, an expressed lack of interest in travelling may be a default response if the perceived costs of travel or barriers associated with travel outweigh the perceived benefits (Shaw \& Coles 
2005, Small et al 2012). Figueiredo et all (2012) point out that the barriers and constraints this population face in everyday life become more challenging within a tourism context due to the unfamiliarity with the environment/supports, while many caregivers wonder if the need to compromise choices, social exclusion that may come from travel and the magnified planning demands make it easier to stay at home (MacTavish et al 2009; Darcy, 2002). Blichfeldt \& Nicolaisen (2011) also commented that the antistructural nature of tourism runs in stark contrast to the highly structured lives of many people with disabilities particularly those with behavioural considerations, sometimes raising the stress levels beyond those they are comfortable with.

\section{Tier 4: the Moderating Factors of 'Impairment effects'}

Lastly, the fourth tier acknowledges that individual impairment effects on people within a group may affect their ability to travel. Freeman \& Selmi (2010) assert that the impact of identical barriers on individuals can vary significantly because of the differences in the individual's psychology combined with the nature and level of support needs. Yet, it is the concept of 'impairment effects', the direct embodied and unavoidable impacts that impairments have on individuals' functioning (Thomas, 2010: 37) constitute a fourth tier. The identification of 'impairment effects' is well recognised in theorising disability in broader management disciplines (Williams \& Maven, 2012) but has had little theoretical impact on tourism research.

In tourism, the severity, congenital nature or age of onset, and the ability to accept, adjust to the disability and the presence of single or multiple disabilities are key determinants. Severity is recognized as axiomatic in much of the literature, as categorizations refer alternately to differing levels of ability (Buhalis et al 2005) or support needs (Darcy 2010). The Yau, McKercher \& Packer (2004) study of the process by which people with disabilities became travel active noted disabling conditions are either congenital or acquired with acquired conditions being either of acute or insidious onset. Most of the respondents in this study felt it was preferable to have a sudden onset rather than a slow, progressive deterioration of a condition, for while traumatic, it forced the individual, and his or her family and friends to begin the adjustment process 
immediately. Likewise, the presence of multiple disabilities adds greater complexity to understanding and providing transformative solutions for tourists needs (Darcy 2010).

Accommodating for individual impairment effects requires a higher level of service provision for these individuals across the tourism system. In essence, this may be as simple as for some individuals who have issues with temperature management to control their body temperatures and therefore must be careful to control their core temperatures may seek transport, accommodation and attractions that can offer air-conditioning or heating depending on the climate. For others it has to do with medication and equipment provision for undertaking daily regimes. These effects should sit comfortably at least as a conceptual level with tourism and hospitality providers who are used to customising their service provision for individuals with all types of needs from luxury travellers (Knutson, Stevens, Patton, \& Thompson, 1993) through to those with dietary requirements, chemical free environments and pet friendly organisations (Carr \& Cohen, 2009; Dolnicar, 2015; Razzaq, Hall, \& Prayag, 2016).

\section{Discussion and Conclusion}

The purpose of this paper is to recognise the nature and range of barriers that affect tourism participation among people with disabilities is far more subtle and complex than often portrayed. It is common for this group to be treated as a being a single homogeneous group facing similar constraints that can be resolved with similar solutions. Such assumptions are especially evident among industry workers who have had little or no experience with this community and by government tourism agencies who are keen to be seen to be socially responsible tourism by identifying people with disabilities as an under-developed group with huge market potential. Ironically, this belief is abetted unwillingly by advocacy groups, for it is in their best political interests to use the largest, legitimate numbers possible when arguing about the size, needs and potential economic and political potential of this market, without necessarily adding the caveat that they include people across all need levels of severity and support needs. For example, the English Tourism Council uses the estimate of $15 \%$ of the population having some form of 
disability as a means of attempting to highlight the market potential of this sector (Shaw \& Coles 2004). Likewise, Tourism Victoria (TV 2016) quotes the official WHO figure of one billion while the European Commission (EC 2017) and combines this with an older figure of 650 million people with disabilities, but then adds, when family members are included, two billion people or a third of the world's population are directly affected by disability.

While the sheer numbers may seem impressive, they, in fact, misrepresent the real situation. A Tourism Research Australia report suggests only one percent of people with disabilities suggested they did not travel due to their impairment but noted intrapersonal, environmental and attitudinal constraints as the major reasons for not travelling (Darcy, 2003). Other studies cited above indicate that many people with low to moderate support need disabilities face few real constraints to travel. In reality, not all PWD are interested in travel, and those who are face many of the same types of intrapersonal, interpersonal and structural constaints common to the general popualtion. Additionally, though, all PWD have to negotiate a series of constraints fuelled mostly by ignorance and fear of the other, that leads to the industry overlooking, omitting or just not addressing the group. But, beyond these common issues, members of each disability categtory face their own unqiue issues that may not apply to members of other groups, and even within each disability group, people with different impairment effects, must resolve different sets of issues (Kastenholz, Eusébio \& Figueiredo 2015, WHO 2015).

The four tier framework captures this increasing specificity of needs, by grouping barriers from those that affect all people to issues that are unique to individuals. The tourism literature suggests that barriers operate in a hierarchical manner, with Mactavish, MacKay, Iwasaki \& Betteridge (2007) assert that the typical hierarchical structure found in the leisure constraints literature may not be applicable when considering people with disabilities. In reality, these tiers likely operate both hierarchically and interactively. Barriers can be considered as hierarchical, for issues that appear at each tier must be resolved before travel can occur or can be enjoyed fully. Lower tier barriers represent more fundamental issues whose failure to address renders upper tier issues irrelevant. For example, a genuine lack of interest or not enough interest in travelling can become an irresolvable prohibitor, regardless the resolution of all other barriers has occurred. 
Likewise, lack of money, especially for those people with disabilities who are not in the workforce can stop travel. In a similar manner, Tier 2 barriers that are common to all people with disabilities must be resolved before Tier 3 barriers can be considered.

But, at the same time, interactivity is enhanced and, hence more problematic, in a tourism context where engagement is both multi-faceted and ongoing, whereas much of the work on leisure constraints has a single activity focus (Darcy, Lock, \& Taylor, 2017; Packer, McKercher, $\&$ Yau, 2007). Moreover, issues that appear at a higher tier level may manifest themselves at lower levels. For example, as noted with parents of children with disabilities, an expressed lack of interest may reflect the cumulative impact of different barriers at multiple levels that restrict travel. In a similar manner, specific impairment needs may also emerge as causal factors for lower tier barriers. People with high support needs may face greater financial costs associated with travel, be subjected to more negative attitudes and a greater sense of social exclusion than people with fewer support needs. The same may also be true depending on the age of the person and the degree of visibility of the disability. A senior with a hidden disability, such as heart disease may be treated very differently than a younger person with a more visible disability. Moreover, the impact of many barriers is multiplicative. People may be able to negotiate single constraints, but their ability and willingness to negotiate multiple constraints or the unknown nature of constraints in destinations many thousands of kilometres from their place of residence may require more effort than the perceived benefit.

Lastly, the creation of any framework of this type must appreciate its dynamic nature and that a range of moderating and modifying factors as identified by impairment effects in Tier 4 may accentuate or diminish the impact of individual issues raised. Lyu, Oh \& Lee (2013) remind us that constraints do not necessarily restrict or preclude participation. Instead different strategies can be adopted to overcome or minimize them to such an extent that participation can occur (Blichfeldt \& Nicolaisen 2011, Lee Agarwal \& Kim 2012). At the same time, emerging technologies are beginning to address some tier 3 and 4 barriers. Yet, as people with disability (across all categories of disability and support needs) have continually reported in the literature to researchers as well as by media reports of critical incidents, their journey to negotiate barriers 
is ongoing and interactive with every stage of the journey, every destination they reach and every tourist experience that they undertake.

As we identified at the start of the paper, the research was not exhaustive of all studies carried out on disability, tourism or accessible tourism, or barriers and constraints research. Rather the paper set to propose a way of conceptualising a body of research across these areas of study used to assist researchers to articulate their contributions more clearly in these areas of research. The four tiered approach contributes to work within tourism studies by explicitly introducing key influences from disability studies on understanding the individual impairment effects, the considerations this has for embodied understandings of tourism and to assist with the clearer articulation of the positioning of new studies. We suggest that future research draws upon such a conceptualisation to provide a more nuanced understanding of the lived experience of the heterogeneous nature of disability types and support needs in a highly interactive tourism environment.

\section{References}

Australian Bureau of Statistics. (2015). Disability, Ageing and Carers, Australia: Summary of Findings, 2015 (Cat No. 4430.0) Canberra: Australian Bureau of Statistics.

Barnes, C., Mercer, G., \& Shakespeare, T. (2010). Exploring disability: a sociological introduction (2nd ed.). Malden, Mass: Polity Press.

Bergier, J. \& Kubińska, Z. (2010) Environmental Determinants of Participation in Tourism and Recreation of People with Varying Degrees of Disability. Journal of Toxicology and Environmental Health, Part A 73(17-18): 1134-1140, DOI:

10.1080/15287394.2010.491042

Blichfeldt, B. \& J. Nicolaisen (2011) Disabled travel: not easy, but doable. Current Issues in Tourism, 14(1): 79-102.

Bolt, D. (2014). Changing Social Attitudes Toward Disability: Perspectives from Historical, Cultural, and Educational Studies: Routledge. 
Buhalis, D \& Darcy S. (Eds) (2011) Accessible Tourism: Concepts and Issues. Bristol: Channel View Publications.

Buhalis, D., Eichhorn, V., Michopoulou, E \& Miller, G. (2005) Accessibility Market and Stakeholder Analysis: One-Stop-Shop for Accessible Tourism in Europe (OSSATE). http://www.accessibletourism.org/resources/ossate_market_analysis_public_final.pdf $<$ downloaded Mar 17, 2017>.

Buhalis, D., \& Michopoulou, E. (2011). Information-enabled tourism destination marketing: Addressing the accessibility market. Current Issues in Tourism, 14(2), 145-168.

Carr, N., \& Cohen, S. (2009). Holidaying with the Family Pet: No Dogs Allowed! Tourism and Hospitality Research, 9(4), 290-304.

Chang, Y. C. \& Chen, C. F. (2011) Identifying mobility service needs for disabled air passengers. Tourism Management 32(5): 1214-1217

Crawford, D. \& Godbey, G. (1987) Reconceptualising barriers to family leisure. Leisure Sciences, 9 (2): 119-127

Crawford, D., Jackson, E., \& Godbey, G. (1991) A hierarchical model of leisure constraints. Leisure Sciences 13(4): 309 - 320

CSD (2015) Hong Kong Monthly Digest of Statistics: Persons with Disabilities and Chronic Diseases in Hong Kong. Hong Kong Census and Statistics Department. http://www.statistics.gov.hk/pub/B71501FB2015XXXXB0100.pdf $<$ downloaded Mar 16, 2017>.

Daniels, M., Drogin Rodgers, E., \& Wiggins, B. (2005) “Travel Tales": an interpretive analysis of constraints and negotiations to pleasure travel as experienced by persons with physical disabilities. Tourism Management 26:919-930.

Darcy, S. (2002) Marginalised Participation: Physical Disability, High Support Needs and Tourism Journal of Hospitality and Tourism Management 9 (1):61 - 72

Darcy, S. (1998). Anxiety to access: tourism patterns and experiences of New South Wales people with a physical disability. Sydney: Tourism New South Wales.

Darcy, S. (2002). Marginalised participation: Physical disability, high support needs and tourism. Journal of Hospitality and Tourism Management, 9(1), 61-72. 
Darcy, S. (2003). Disabling journeys: The tourism patterns of people with impairments in Australia. Paper presented at the Riding the Wave of Tourism and Hospitality Research, CAUTHE - Southern Cross University, Lismore.

Darcy, S. (2010) Inherent complexity: Disability, accessible tourism and accommodation information preferences. Tourism Management 31(6): 816-826.

Darcy, S. (2012). (Dis)Embodied Air Travel Experiences: Disability, Discrimination and the Affect of a Discontinuous Air Travel Chain. Journal of Hospitality and Tourism Management, 19(e8 August), 1-11.

Darcy, S. (2013) Tourism and disability. In Lovelock B \& Lovelock K (Eds) The Ethics of Tourism: Critical and Applied Perspectives. London: Routledge pp 169-197.

Darcy, S., \& Taylor, T. (2009) Disability citizenship: An Australian human rights analysis of the cultural industries. Leisure Studies, 28(4): 419-441.

Darcy, S., Ambrose, I., Schweinsberg, S. \& Buhalis. D (2011) Conclusion: Universal approaches to accessible tourism. In Buhalis, D \& Darcy S. (Eds) (2011) Accessible Tourism: Concepts and Issues. Bristol: Channel View Publications. pp 300-311.

Darcy, S. \& Buhalis. D (2011) Introduction: From Disabled Tourists to Accessible Tourism. In Buhalis, D \& Darcy S. (Eds) (2011) Accessible Tourism: Concepts and Issues. Bristol: Channel View Publications. pp 1-20

Darcy, S., \& Pegg, S. (2011) Towards Strategic Intent: Perceptions of disability service provision amongst hotel accommodation managers. International Journal of Hospitality Management. 30(2): 468-476.

Darcy, S., Lock, D., \& Taylor, T. (2017). Enabling Inclusive Sport Participation: Effects of Disability and Support Needs on Constraints to Sport Participation. Leisure Sciences, 39(1), 20-41.

Daruwalla, P., \& Darcy, S. (2005) Personal and societal attitudes to disability. Annals of Tourism Research 32(3):549-570.

Dickson, T. J., Darcy, S., Johns, R., \& Pentifallo, C. (2016). Inclusive by design: transformative services and sport-event accessibility. The Service Industries Journal, 36(11-12), 532555. 
Dolnicar, S. (2015). Environmentally sustainable tourists. In C. M. Hall, S. Gössling \& D. Scott (Eds.), The Routledge handbook of tourism and sustainability (pp. 140-150): Routledge.

Dolnicar, S., Lazarevski, K, Yanamandram, V. (2013) Quality of life and tourism: A conceptual framework and novel segmentation base. Journal of Business Research. 66(6) 724-729.

Dwyer, L. \& Darcy, S. (2011) Economic Contribution of Tourists with Disabilities: An Australian approach and methodology. In Buhalis, D \& Darcy S. (Eds) (2011) Accessible Tourism: Concepts and Issues. Bristol: Channel View Publications. pp 214-240.

EC (2017) Accessible Tourism. European Commission. http://ec.europa.eu/growth/sectors/tourism/offer/accessible en $<$ downloaded Nov 23, 2017).

Eichhorn, V. \& Buhalis, D. (2011) Accessibility: Key Objectives for the Tourism Industry, In Buhalis, D \& Darcy S. (Eds) Accessible Tourism: Concepts and Issues. Bristol: Channel View Publications. pp 46-61.

Figueiredo, E., Eusebio, C. \& Kastenholz, E. (2012) How Diverse are Tourists with Disabilities? A Pilot Study on Accessible Leisure Tourism Experiences in Portugal. International Journal of Tourism Research 14(6): 531-550.

Freeman, I., \& Selmi, N. (2010) French versus Canadian Tourism: Response to the Disabled. Journal of Travel Research 49(4): 471-485.

Gilbert, D., \& Hudson, S (2000) Tourism demand constraints: A skiing participation. Annals of Tourism Research 27(4):906-925.

Goffman, E. (2010). Selections from Stigma. In L. J. Davis (Ed.), The Disability Studies Reader (3rd ed., pp. 203-216). London: Routledge.

Jackson, E. L., Crawford, D. W., \& Godbey, G. (1993). Negotiation of leisure constraints. Leisure Sciences, 15(1), 1-11.

Kastenholz, E., Eusébio, C., \& Figueiredo, E. (2015) Contributions of tourism to social inclusion of persons with disability. Disability \& Society, 30(8) 1259-1281, DOI: $10.1080 / 09687599.2015 .1075868$

Kim, S. \& Lehto, X. (2012) The voice of tourists with mobility disabilities: insights from online customer complaint websites. International Journal of Contemporary Hospitality Management, 24(3): 451 - 476. 
http://scholarworks.umass.edu/gradconf hospitality/2011/Presentation/41/ $<$ downloaded Mar 17, 2017>.

Kim, S. \& Lehto, X. (2013) Travel by families with children possessing disabilities: Motives and activities. Tourism Management 37:13-24.

Knutson, B., Stevens, P., Patton, M., \& Thompson, C. (1993). Consumers' Expectations for Service Quality in Economy, Mid-Price and Luxury Hotels. Journal of Hospitality \& Leisure Marketing, 1(2), 27-43.

Koutsogeorgou, E., Leonardi, M., Bickenbach, J. E., Cerniauskaite, M., Quintas, R., \& Raggi, A. (2014). Social capital, disability, and usefulness of the International Classification of Functioning, Disability and Health for the development and monitoring of policy interventions. Disability \& Society, 29(7), 1104-1116.

Lee, B. K., Agarwal, S., \& Kim, H. J. (2012). Influences of travel constraints on the people with disabilities' intention to travel: An application of Seligman's helplessness theory. Tourism Management, 33(3), 569-579.

Lee S. H. \& Tideswell, C. (2005). Understanding attitudes toward leisure travel and the constraints faced by senior Koreans. Journal of Vacation Marketing 11(3): 249-263.

Litvin, S. W., Smith, W. W., \& Pitts, R. E. (2013). Sedentary Behavior of the Non-travel Segment: A Research Note. Journal of Travel Research, 52(1): 131-136.

Luther, A. (2013) Tourists with Severe Disability In Botterill, G. Pennings, T. Mainil (Eds). Medical Tourism and Transnational Health Care. New York: Palgrave McMillan, pp 6482.

Lyu, S., Oh, C., \& Lee, H. (2013) The Influence of Extraversion on Leisure Constraints Negotiation Process: A Case of Korean people with Disabilities. Journal of Leisure Research 45(2): 233-252.

Mactavish, J., Mackay, K., Iwasaki, Y., \& Betteridge, D. (2007) Family Caregivers of Individuals with Intellectual Disability: Perspectives on Life Quality and the Role of Vacations. Journal of Leisure Research 39(1): 127-155.

Mak J., Carlisle L., \& Dai, S. (2005). Impact of population aging on Japanese international Travel to 2025. Journal of Travel Research 44(2): 151-162. 
McGuire, F. A., Dottavio, D., \& O'Leary, J. T. (1986). Constraints to participation in outdoor recreation across the life span: A nationwide study of limitors and prohibitors. The Gerontologist, 26(5), 538-544.

McKercher, B (2009) Non-travel by Hong Kong Residents. International Journal of Tourism Research. 11(6): 507 - 519.

McKercher B., T. Packer, M. Yau and Lam, P. (2003) Travel Agents: facilitators or inhibitors of travel for people with disabilities? Tourism Management 24 (4): 465 - 474.

McKercher, B. \& Prideaux, B. (2014) Academic Myths of Tourism. Annals of Tourism Research. 46: 16-28.

McKercher, B., \& Chen, F. (2015) Travel as a Life Priority? Asia Pacific Journal of Tourism Research. 20(7): 715-729.

Mills, J. E., Han, J.-H., \& Clay, J. M. (2008). Accessibility of Hospitality and Tourism Websites: A Challenge for Visually Impaired Persons. Cornell Hospitality Quarterly, 49(1), 28-41.

Muloin, S. (1992) Wilderness Access for Persons with a Disability, in (Harper, G, Weiler, B, eds) Ecotourism, Australian Bureau of Tourism Research, pp 20 - 25

Murray, M. \& Sproats, J. (1990) The Disabled Traveller: Tourism and Disability in Australia, Journal of Tourism Studies, 1(1): 9 - 14

Nicolaisen, J., Blichfeldt, B \& Sonnenschein, F. (2012) Medical and social models of disability: a tourism providers' perspective. World Leisure Journal, 54(3) 201-214. DOI: 10.1080/04419057.2012.702451.

Nyaupane, G. \& Andereck, K. (2008). Understanding Travel Constraints: Application and extension of a leisure constraints model. Journal of Travel Research 46(4): 433-439.

Oliver, M. (1990). The Politics of Disablement. Basingstoke, Houndmills: Macmillan.

O'Neill, M. \& Knight, J. (2000) Disability Tourism Dollars in Western Australia Hotels. Hospitality Review 18(2), Article 7. http://digitalcommons.fiu.edu/hospitalityreview/vol18/iss $2 / 7<$ downloaded Mar 17. $\underline{2017>}$.

Packer, T. L., McKercher, B., \& Yau, M. (2007). Understanding the complex interplay between tourism, disability and environmental contexts. Disability \& Rehabilitation, 29(4), 281292. 
Patterson, I \& Pegg, S. (2011) Aging travellers: Seeking an experience - not just a destination. In Buhalis, D \& Darcy S. (Eds) (2011) Accessible Tourism: Concepts and Issues. Bristol: Channel View Publications. Pp 174-190.

Perry, H. \& Kozub, M. (2011) Family travel Experiences When One Member Has a Developmental Disability. Proceedings of the 2011 Northeastern Recreation Research Symposium. http://scholarworks.umass.edu/nerr/2011/Papers/17/

Pettigrew, T. F., \& Tropp, L. R. (2006). A meta-analytic test of intergroup contact theory. Journal of personality and social psychology, 90(5), 751-783.

Poria, Y., Reichel, A., \& Brandt, Y. (2010) The Flight Experiences of People with Disabilities: An Exploratory Study. Journal of Travel Research 49(2): 216-227.

Ray, N., \& Ryder, M. (2003) Ebilities" tourism: an exploratory discussion of the travel needs and motivations of the mobility-disabled. Tourism Management 24(1): 57-72.

Razzaq, S., Hall, C. M., \& Prayag, G. (2016). The capacity of New Zealand to accommodate the halal tourism market — Or not. Tourism Management Perspectives, 18, 92-97.

Richards, V., Pritchard, A., \& Morgan, N. (2010) (Re)Envisioning tourism and visual impairment. Annals of Tourism Research 37(4): 1097-1116.

Shakespeare, T. (2017) The Social Model of Disability. in Davis, L (Ed) The Disabilities Studies Reader. New York :Routledge. Pp 195 - 203.

Shaw, G, \& Coles, T. (2004) Disability, holiday making and the tourism industry in the UK: a preliminary survey. Tourism Management. 25:397-403

Shi, Y. Q. (2006). The accessibility of Queensland visitor information centres' websites. [Article]. Tourism Management, 27(5), 829-841.

Small, J. (2015). Interconnecting mobilities on tour: tourists with vision impairment partnered with sighted tourists. Tourism Geographies, 17(1), 76-90.

Small, J., Darcy, S., \& Packer, T. (2012). The embodied tourist experiences of people with vision impairment: Management implications beyond the visual gaze. Tourism Management, 33(4), 941-950.

Smith, R. W. (1987) Leisure of Disabled Tourists: Barriers to Travel, Annals of Tourism Research, 14(3): 376 - 389. 
Thomas, C. (1999). Female Forms: Experiencing and understanding disability. Buckingham: Open University Press.

Thomas, C. (2004). Disability and impairment. In J. Swain, S. French, C. Barnes \& C. Thomas (Eds.), Disabling barriers-Enabling environments (pp. 21-28). London: SAGE.

Thomson, R. G. (1997). Extraordinary bodies: figuring physical disability in American culture and literature. New York: Columbia University Press.

TV (2016) Accessible tourism. Tourism Victoria. http://www.tourism.vic.gov.au/business-toolssupport/accessible-tourism.html < downloaded Mar 16, $2017>$.

United Nations. (2006). Convention on the Rights of Persons with Disabilities. New York: http://www.un.org/disabilities/convention/conventionfull.shtml: United Nations General Assembly A/61/611 - 6 December 2006.

UNWTO - (2016) Manual on Accessible Tourism for All: Principles, Tools and Best Practices Module I: Accessible Tourism - Definition and Context http://www.eunwto.org/doi/pdf/10.18111/9789284418077< downloaded Mar 17, $2017>$.

WHO (2001). International Classification of Functioning, Disability and Health (ICIDH-2). Geneva: World Health Organization.

WHO (2002). Towards a Common Language for Functioning, Disability and Health - ICF. Geneva: World Health Organization

WHO (2015) WHO Global Disability Action Plan 2014 - 2021: Better health for all people with disability. Geneva: World Health Organization. http://apps.who.int/iris/bitstream/10665/199544/1/9789241509619_eng.pdf $<$ downloaded Mar 16, 2017>.

Williams, J., \& Mavin, S. (2012). Disability as Constructed Difference: A Literature Review and Research Agenda for Management and Organization Studies. International Journal of Management Reviews, 14(2), 159-179.

Williams, R., Rattray, R., \& Grimes, A. (2006). Meeting the On-line Needs of Disabled Tourists: an Assessment of UK-based Hotel Websites. International Journal of Tourism Research, $8(1), 59$. 
World Health Organization, \& World Bank. (2011). World Report on Disability, from http://www.who.int/disabilities/world report/2011/report/en/index.html $<$ downloaded Nov 23, 2017>.

Yau, M., B. McKercher \& T. Packer (2004) Travelling with a Disability: More than just an access issue Annals of Tourism Research 31(4): 946 - 960.

Zajadacz, A. (2014) Sources of tourist information used by Deaf people. Case study: the Polish Deaf Community. Current Issues in Tourism, 17(5): 434-454, DOI: 10.1080/13683500.2012.725713.

Zajadacz, A. (2015) Evolution of models of disability as a basis for further policy changes in accessible tourism. Journal of Tourism Futures. 1(3): 189- 202. 
Figure 1

Hierarchy of Barriers to Travel by People with Disabilities
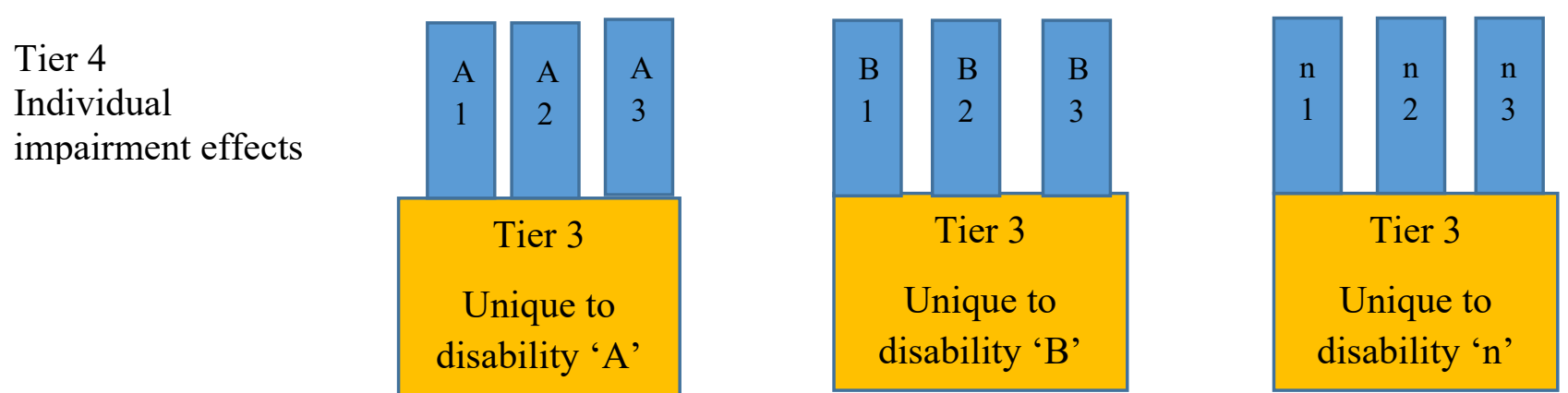

Tier 2

Common to all people with disabilities

\section{Ignorance \\ Attitude}

Information

Industry

The individual

Tier 1

Common to all people
Structural
Interpersonal
Intrapersonal
Interest 